\title{
High Temperature Fatigue Crack Growth Rate Studies in Stainless Steel 316L(N) Welds Processed by A-TIG and MP-TIG Welding.
}

\author{
Manuel Thomas ${ }^{1}$, Raghu V. Prakash ${ }^{1 *}$, Ganesh Sundara Raman $\mathrm{S}^{3}$ and Vasudevan, M. ${ }^{4}$ \\ ${ }^{1}$ Department of Mechanical Engineering, IIT Madras, 600036 Chennai, India \\ ${ }^{2}$ Department of Mechanical Engineering, IIT Madras, 600036 Chennai, India \\ ${ }^{3}$ Department of Metallurgical and Materials Engineering, IIT Madras, 600036 Chennai, India \\ ${ }^{4}$ Indira Gandhi Centre for Atomic Research, 603102, Kalpakkam, India
}

\begin{abstract}
Welded stainless steel components used in power plants and chemical industries are subjected to mechanical load cycles at elevated temperatures which result in early fatigue failures. The presence of weld makes the component to be liable to failure in view of residual stresses at the weld region or in the neighboring heat affected zone apart from weld defects. Austenitic stainless steels are often welded using Tungsten Inert Gas (TIG) process. In case of single pass welding, there is a reduced weld penetration which results in a low depth-to-width ratio of weld bead). If the number of passes is increased (Multi-Pass TIG welding), it results in weld distortion and subsequent residual stress generation. The activated flux TIG welding, a variant of TIG welding developed by E.O. Paton Institute, is found to reduce the limitation of conventional TIG welding, resulting in a higher depth of penetration using a single pass, reduced weld distortion and higher welding speeds. This paper presents the fatigue crack growth rate characteristics at $823 \mathrm{~K}$ temperature in type $316 \mathrm{LN}$ stainless steel plates joined by conventional multi-pass TIG (MP-TIG) and Activated TIG (A-TIG) welding process. Fatigue tests were conducted to characterize the crack growth rates of base metal, HAZ and Weld Metal for A-TIG and MPTIG configurations. Micro structural evaluation of $316 \mathrm{LN}$ base metal suggests a primary austenite phase, whereas, A-TIG weld joints show an equiaxed grain distribution along the weld center and complete penetration during welding (Fig. 1). MP-TIG microstructure shows a highly inhomogeneous microstructure, with grain orientation changing along the interface of each pass. This results in tortuous crack growth in case of MP-TIG welded specimens. Scanning electron microscopy studies have helped to better understand the fatigue crack propagation modes during high temperature testing.
\end{abstract}

\section{Introduction}

The Austenitic Stainless steels are known to possess adequate high-temperature physical properties and excellent corrosion resistance. By virtue of this, Austenitic Stainless steels are routinely used as structural members in chemical industries and power plants. The low carbon grade of austenitic stainless steels $(316 \mathrm{~L}$, 304L), normally designated as L grades is commonly used in applications where high resistance to intergranular corrosion is desirable [1]. The addition of nitrogen in a small amount (up to $0.08 \mathrm{wt} \%$ ) is known to improve the mechanical strength and impart improved creep resistance [2-5]. The improved creep resistance in the temperature range of $500-600^{\circ} \mathrm{C}$ makes the type $316 \mathrm{~L}(\mathrm{~N})$, as the most widely used material for the power plant components.

Welding is often being used in the fabrication of power plant structural components. The presence of weld can compromise the structural integrity, as the weld often acts as a site for the defect. When exposed to the cyclic loads, it can act as a fatigue crack initiation site, which leads to further propagation by fatigue and fast fracture, thus, making it necessary to estimate the crack growth rates in the welds for life prediction.
The available literature presents the details of the effect of different welding process on the fatigue behavior for variety of austenitic stainless-steel weldments [6]. These studies indicate a reduction in crack growth rates in the weldments compared to the base metal. Mills [1] has conducted a detailed review of the fracture toughness of austenitic stainless steels (SS304 and SS316) and it welds, and has observed the significant variation in the mechanical properties and fracture toughness of the material, depending on the welding process adopted. Shahinian and James[7-10] observed significant disparity in the crack growth rates of SS316 welds prepared using different flux and filler materials, thus, indicating the effect of welding technique on the fatigue crack growth rate. As many of the power plant components work at a high temperature for a considerable period of time, it is important to understand the fatigue response of the SS304L(N) and SS316L(N) material and its welds to better estimate the life.

The present work presents the high-temperature fatigue crack growth in type $316 \mathrm{~L}(\mathrm{~N})$ stainless steel welds, joined using two processes: a) conventional multi-pass TIG (MP-TIG) and b) Activated Flux TIG (A-TIG) welding process. It may be noted that the welding of metals using conventional TIG process is

* Corresponding author: raghuprakash@,iitm.ac.in 
limited by the thickness of material that can be joined as one needs to avoid lack of penetration. The use of conventional TIG for the joining the stainless steel is limited to plates having a maximum thickness of $3 \mathrm{~mm}$, which is a serious limitation [12] for many power plant component building. Further, it is noted from the literature that variable penetration rates are exhibited by the stainless steels of different heats (or batches) during TIG welding. The use of multiple passes for achieving the increased penetration may result in low productivity, weld distortion, shrinkage and residual tensile stress.

Activated flux TIG (A-TIG) welding is a variant of TIG welding, developed by E.O. Paton Electric Welding Research Institute [13]. Higher depth of weld penetration is possible in A-TIG welding, making it suitable for joining thicker plates in a single pass, thereby increasing the productivity [13]. The A-TIG welding process involves the use of an electronegative flux, applied to the surface to be welded which tends to constrict the arc, thereby increasing the current density. This results in the higher weld penetration and faster welding.

For the present study, an indigenously developed multi-component flux is used for the A-TIG welding. This study is intended to evaluate the fatigue crack performance of welds produces using indigenously developed A-TIG welding and compare it with the conventional MP-TIG weld.

\section{Experimental Methods}

The chemical composition of the base metal and weld is presented in Table 1. The welded plates of $5 \mathrm{~mm}$ thickness $316 \mathrm{~L}(\mathrm{~N})$ were prepared using MP-TIG, A-TIG welding technique. A layer of flux having patented composition has been applied on the surface of the plates to be welded. It may be noted that the A-TIG welding process was completed in a single pass with out the use of any filler wires. The filler wires of $316 \mathrm{~L}$ were used in the preparation of $316 \mathrm{~L}(\mathrm{~N}) \mathrm{MP}-\mathrm{TIG}$ joints. The detailed procedure of the process and parameters used is reported in Ref. 13.
Fatigue crack growth experiments were conducted in accordance to ASTM E647, using a MTS 810 servocontrolled hydraulic actuator system. Compact tensiontype specimens extracted from the weld plates, from the location of Heat affected zone (HAZ) and weld metal bead as indicated in the schematic (Fig. 1). Figure 2 presents the schematic of the $\mathrm{C}(\mathrm{T})$ specimen used for fatigue crack growth rate experiments. The orientation of the machined notch was parallel to the direction of the welding to ensure that the fatigue crack grew along the weld bead (or) in the HAZ that is parallel to the weld bead.

The fatigue crack growth rate testing was conducted at a temperature of $823 \mathrm{~K}\left(550^{\circ} \mathrm{C}\right)$. A three-zone split furnace was used to heat the specimen and maintain the temperature. All the tests were conducted at a constant positive stress ratio (Ratio of minimum to maximum load) of $\mathrm{R}=0.1$. Crack growth rate was estimated based on compliance technique using an Epsilon make High Temperature crack opening displacement gage/The knife edges for mounting the High temperature COD gage was made integral to the $\mathrm{C}(\mathrm{T})$ specimen geometry by wireEDM process. The load-COD response during fatigue cycling was recorded at periodic intervals of $(\sim 750$ cycles) at a low frequency of $0.5 \mathrm{~Hz}$, over 5 cycles in an otherwise constant amplitude load cycling of the specimen at a typical test frequency of $10 \mathrm{~Hz}$.,

The crack length was calculated using unloading compliance method as described by ASTM E-647 test standards. The failed samples were examined using a Quanta-400 FE SE Scanning Electron Microscope to understand the fracture mode details.

\section{Results and Discussion}

\subsection{Microstructure}

The weld macrographs provided in figures 3 and 4 indicates the extent of penetration and the cross-section of the weld bead. A relatively narrow weld bead can be

Table 1. Chemical composition (wt $\%$ ) of type $316 \mathrm{~L}(\mathrm{~N})$ and welds

\begin{tabular}{|l|c|c|c|c|c|c|c|c|c|}
\hline Material & $\mathrm{C}$ & $\mathrm{Mn}$ & $\mathrm{Si}$ & $\mathrm{Cr}$ & $\mathrm{Ni}$ & $\mathrm{Mo}$ & $\mathrm{N}$ & $\mathrm{S}$ & $\mathrm{Fe}$ \\
\hline SS316L(N) & 0.03 & 1.65 & 0.44 & 17.5 & 12.2 & 2.3 & 0.09 & 0.01 & Balance \\
\hline MP-TIG weld & 0.03 & 1.50 & 0.53 & 19.0 & 11.0 & 2.3 & 0.09 & 0.01 & Balance \\
\hline A-TIG weld & 0.03 & 1.45 & 0.50 & 17.5 & 12.0 & 2.4 & 0.09 & 0.01 & Balance \\
\hline
\end{tabular}

The microstructure of the resultant weld joint was analyzed with the help of a Nikon optical microscope. The samples were polished and electrolytically etched to reveal the microstructure. The microhardness profile was obtained over the weld, using Vickers microhardness apparatus. A load of $1.75 \mathrm{~N}$ was applied, with a dwell of $15 \mathrm{~s}$. Indentations were made at base metal, heat affected zone and weldment at regular spacing. observed for the A-TIG joints, while the MP-TIG joints exhibit wider weld geometry. The optical micrograph for the two types of welds indicates that primary austenitic solidification mode was observed irrespective of the type of welding in both the types of welds considered. 


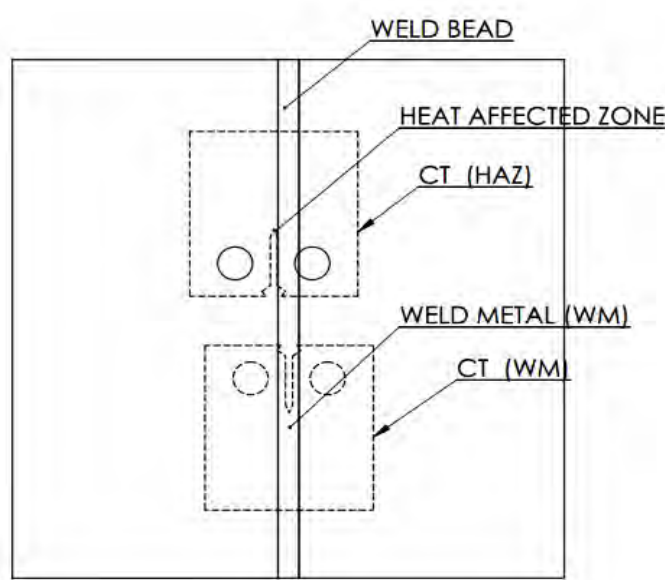

Fig. 1. Compact tension specimen extraction lay out from weld plates.

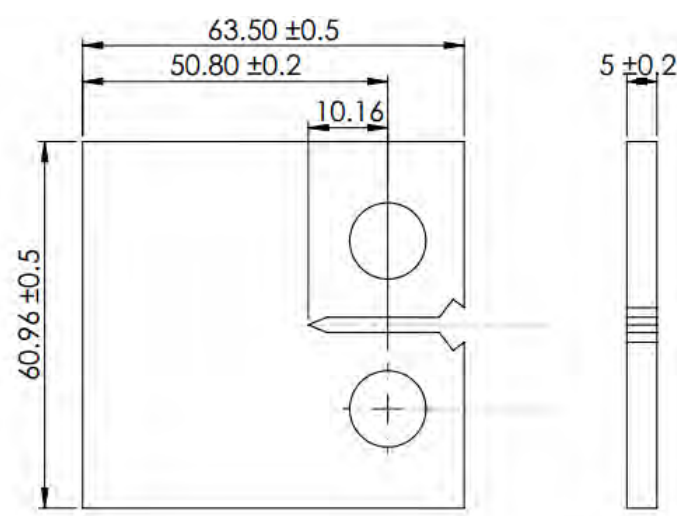

Fig. 2. Schematic of $C(T)$ specimen. All dimensions are in $\mathrm{mm}$.

In case of A-TIG weld metal, fusion zone contained equiaxed growth of grains running parallel to the direction of weld obtained in each weld. Columnar grains are located near the base metal zone, oriented in the transverse direction of welding. Further, it may be noted that in case of A-TIG welding, during solidification, maximum thermal gradient is observed in the transverse direction and the same is indicated from the orientation of columnar grains. The enhanced depth of penetration accounts for the presence of equiaxed grains running through the entire depth of weld. The high heat input in single pass during the welding has resulted in coarse grains in the weld.

In case of MP-TIG joints, the microstructure exhibited random discontinuous distribution of columnar and equiaxed grains. The repeated heating cycles during each pass in welding process has resulted in the highly incoherent distribution of grains (as shown in Figure 3). Thus the effect of thermal cycling due to multi-pass welding is predominant near the region of each weld pass, and the interface of each pass shows a clear change in microstructure. The preferential alignment of grains can be seen normal to each weld pass interface. The grains are observed to be fine in the MP-TIG as the heat input in each pass is lower.

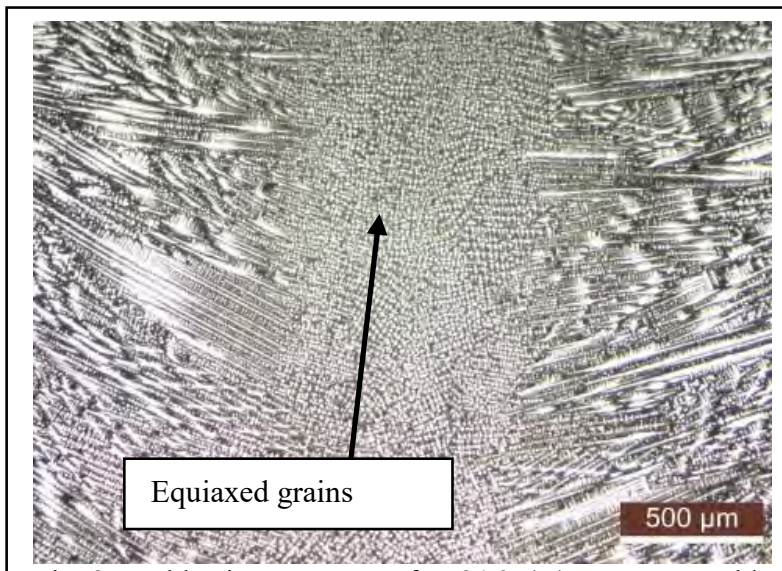

Fig. 3. Weld Microstructure of SS316L(N) A-TIG Weld.

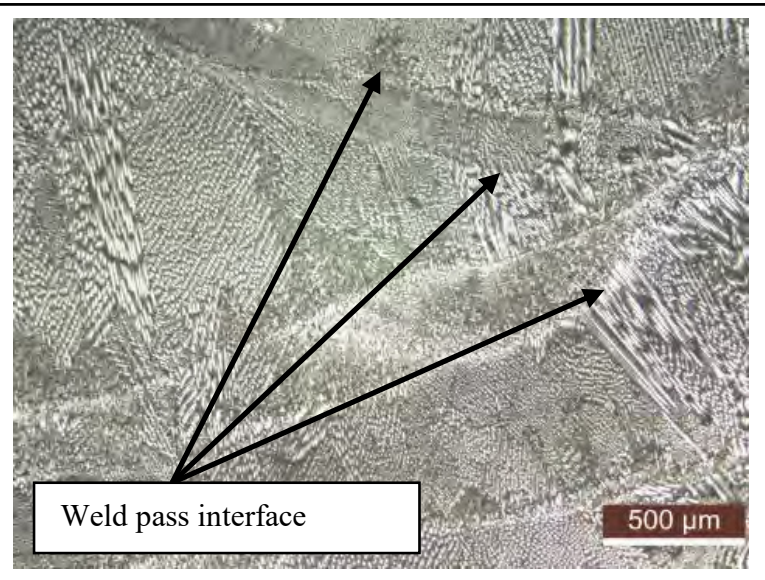

Fig. 4. Microstructure of SS316L(N) MP-TIG Weld.

\subsection{Micro-hardness}

The variation in microhardness over the weld profile is shown in Figures 5 and 6. One can observe a direct correlation between the micro-hardness values and the microstructure. The fusion zone in the A-TIG joints show a reduced hardness value compared to the base metal region. Maximum variation in hardness was observed near the fusion boundary, which corresponds to the region of heat affected zone. Equiaxed grains present at the center of the welded joint showed a maximum hardness, while the adjacent columnar grains showed the minimum value. The slower rate of cooling in A-TIG welds has resulted lower hardness value than the corresponding MP-TIG welds.

The MP-TIG welded joints had higher hardness than its base metal. Higher degree of variation in the hardness can be observed across the weld profile, which can be due to the discontinuous distribution of the grains in MPTIG welding. The zone adjacent to base metal exhibited an abrupt change in hardness, confirming the presence of heat affected zone. The hardness value obtained for MPTIG welds are appreciably higher than its A-TIG counterpart. Repeated thermal cycle during each pass 
and faster cooling rates has promoted formation of finer grains in MP-TIG welds, thereby increasing hardness value.

The MP-TIG welded joints had higher hardness than its base metal. Higher degree of variation in the hardness can be observed across the weld profile, which can be due to the discontinuous distribution of the grains in MPTIG welding. The zone adjacent to base metal exhibited

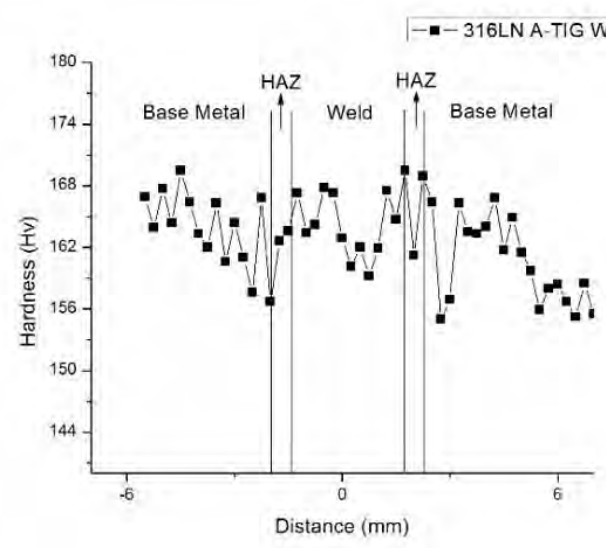

Fig. 5. Microhardness profile of SS316L(N) A-TIG Weld.

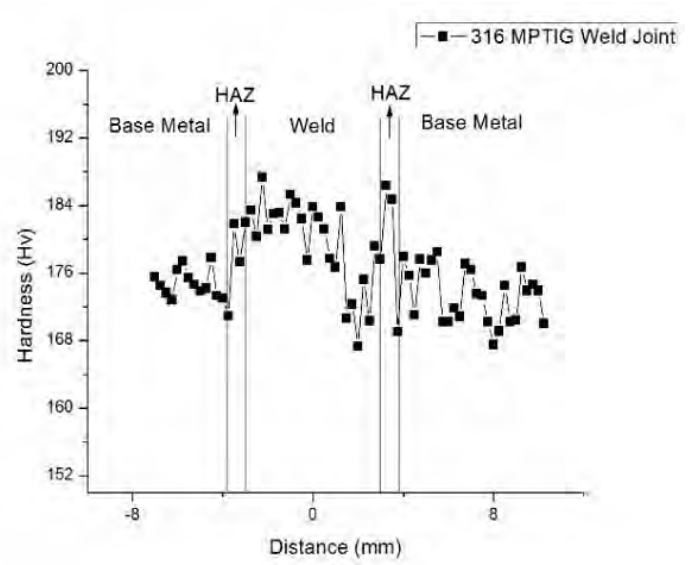

Fig. 6. Microhardness profile of SS316L(N) MP-TIG Weld.

an abrupt change in hardness, confirming the presence of heat affected zone. The hardness value obtained for MPTIG welds are appreciably higher than its A-TIG counterpart. Repeated thermal cycle during each pass and faster cooling rates has promoted formation of finer grains in MP-TIG welds, thereby increasing hardness value.

\subsection{Fatigue crack growth at high temperature}

Fatigue crack growth rate $(\mathrm{da} / \mathrm{dN})$ estimated from crack length versus cumulative number of cycles i.e. a-N curves from experiments conducted at a stress ratio (R) of 0.1 , is plotted as a function of applied stress intensity range. Figure 7 presents the crack growth rate obtained for the base metal, MP-TIG, A-TIG welds at $823 \mathrm{~K}$. The crack growth characteristic for the material in the Heat affected zone region is depicted in Figure 8. It was observed that at the specific high temperature, the crack growth rates exhibited by the weld prepared using MPTIG and A-TIG technique was lower than the parent base metal. Between the MP-TIG and A-TIG weld process, the resistance to the crack growth rate was higher in case of specimens prepared using MP-TIG technique. This could be due to the presence of finer grains in the MP-TIG welded samples. A similar slow down in the crack growth rate was exhibited by the heat affected zone of MP-TIG weld specimens. It is interesting to note that that the fatigue rack growth rates in HAZ of A-TIG weld samples are almost the same as that of the base metal. Thus, the fatigue crack growth rate of weld metal region in A-TIG samples is lower than that of HAZ of A-TIG specimens.

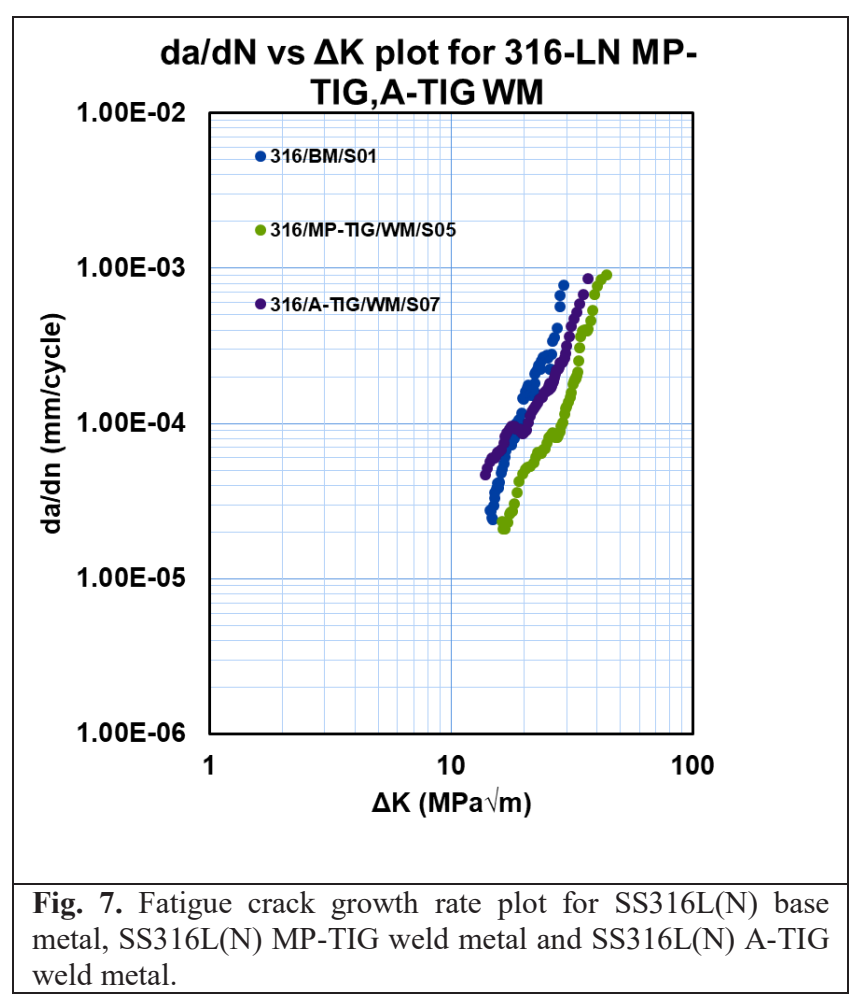

The increased resistance to the crack growth in the MP-TIG welds can be due to the fine-grained microstructure. It could also be due to the repeated thermal cycling during the multi-pass welding that has resulted in highly refined randomly oriented grains, which imparts resistance to the crack growth. The slowdown in fatigue crack growth rate observed at the heat affected zone can be due to the high hardness exhibited by the MP-TIG heat affected zone.

Examination of the fracture surface using scanning electron microscope reveals trans-granular mode of failure in both the welds. Figures 9 and 10 represent the observed fracture surface for the welds joined using MPTIG and A-TIG technique respectively. At regions of low crack growth rate or near the chevron notch initiation zone, the fracture surface is predominantly marked by the presence of river lines and cleavage facets. 
Figures 11 and 12 present the SEM image where the fatigue striations can be seen all along the fracture surface. The fracture surface was found to be rougher for the MP-TIG welds, with herringbone pattern of tear ridges. The MP-TIG welds near the initiation zone exhibit typical quasi-cleavage fracture which is a combination of cleavage facets and tear ridges. The quasi cleavage is typically observed in fine grained structure that is fractured at high temperature. It can further be observed from these SEM images that there is tear ridges between the planes containing striations that run parallel to the direction of crack. The striations are more predominant at intermediate crack growth rates.

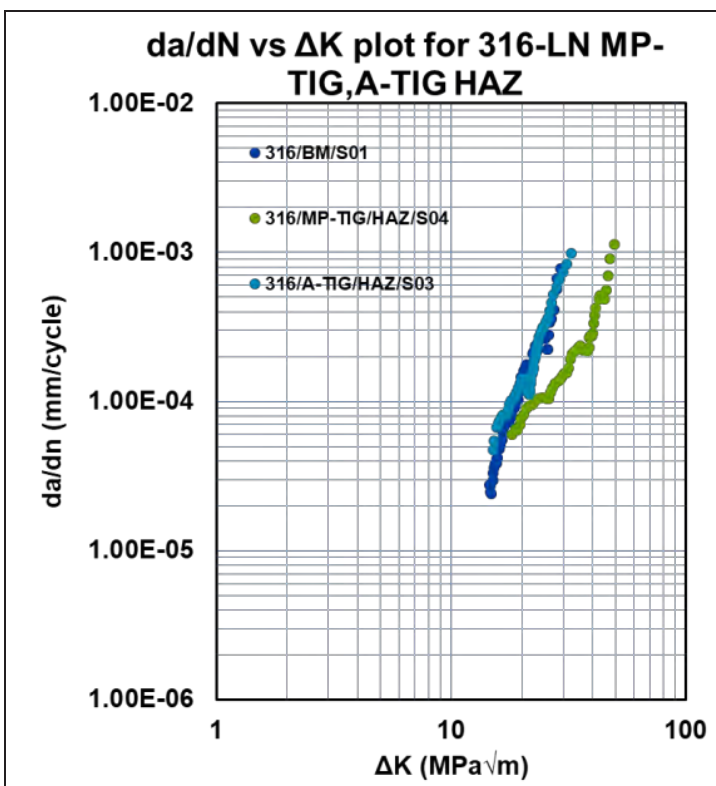

Fig. 8. Fatigue crack growth rate plot for SS316L(N), SS316L(N) MP-TIG weld and SS316L(N) A-TIG in the Heat Affected Zone.

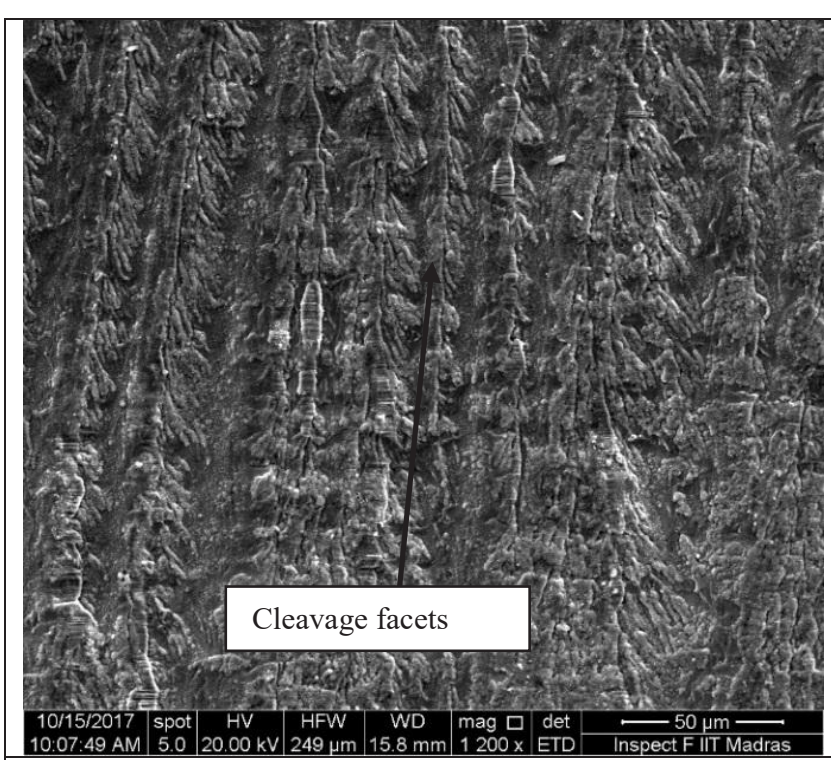

Fig. 9. Trans-granular cleavage facets observed in SS316L(N) MP-TIG welds, at a distance of $\sim 2 \mathrm{~mm}$ from initiation $(\Delta \mathrm{K} \sim$ $15 \mathrm{MPa} \sqrt{\mathrm{m})}$
Figure 13 indicates the fracture surface region near final failure. The final failure in all the specimens was due to ductile mode, marked by fibrous appearance of the fracture surface. With an increase in crack growth rates near the fast fracture region, increased presence of dimples was noticed; void coalescence begins to appear along with the striations. The fast fracture region had considerable presence of dimple structure. The voids that arise from the inclusion or coarser precipitates, get enlarged and during further yielding, can get sheared at the location, giving a fibrous appearance.

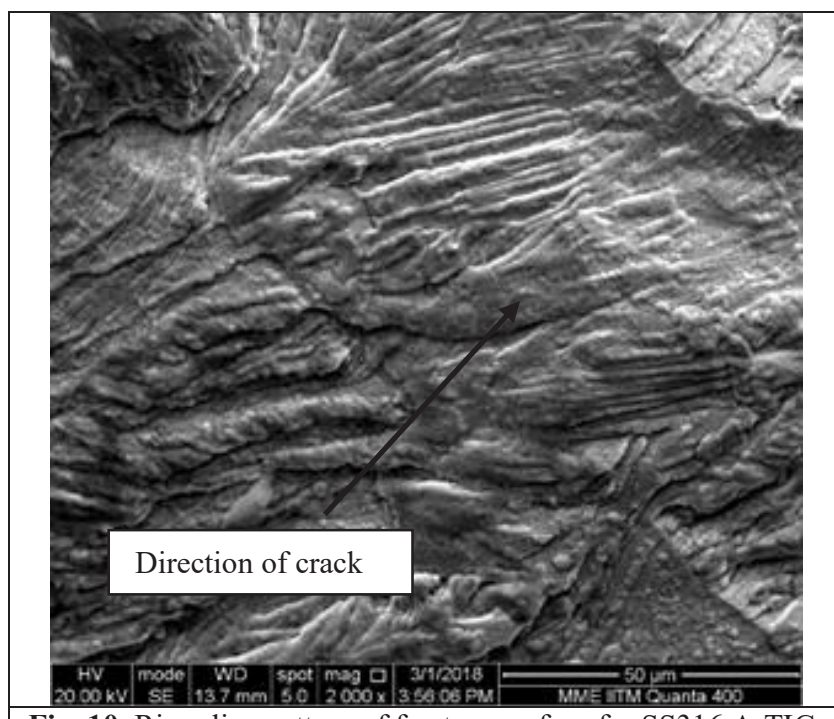

Fig. 10. River line pattern of fracture surface for SS316 A-TIG joint, located at a distance of $\sim 2 \mathrm{~mm}$ from the Chevron notch initiation zone.

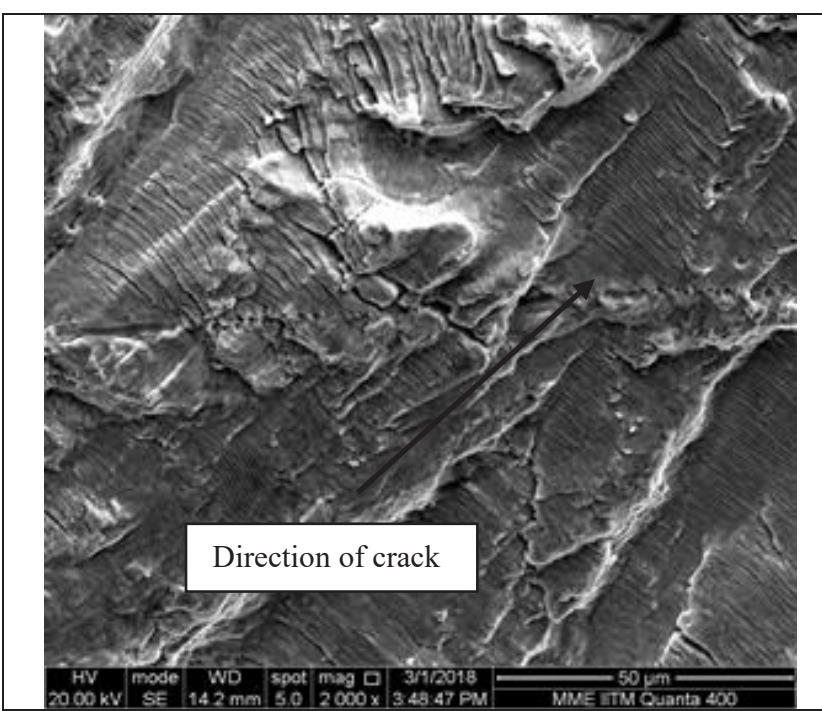

Fig. 11. Observed striation pattern for SS316L(N) A-TIG joint, located at $\sim 10 \mathrm{~mm}$ from initiation zone.

\section{Conclusions}

The high-temperature fatigue crack growth in SS316L(N) metal welds fabricated using MP-TIG and A-TIG technique was investigated experimentally. Ancillary metallographic and fractographic evaluation of the surface was performed to identify the failure mechanism. In all the test cases, the mode of failure 
observed was trans-granular in nature. The rate of crack growth in parent metal (base metal) was found to be faster than that in weld metal, with MP-TIG weld showing better resistance to the crack growth. The weld metal of A-TIG showed reduced crack growth rates for a given stress intensity factor range compared to HAZ region as well as base metal. In the case of MP-TIG weld, the HAZ crack growth rates were considerably slower than base metal. From these perspectives, it would appear reasonable to have MP-TIG has the process for improving the fatigue crack growth rate resistance of material.

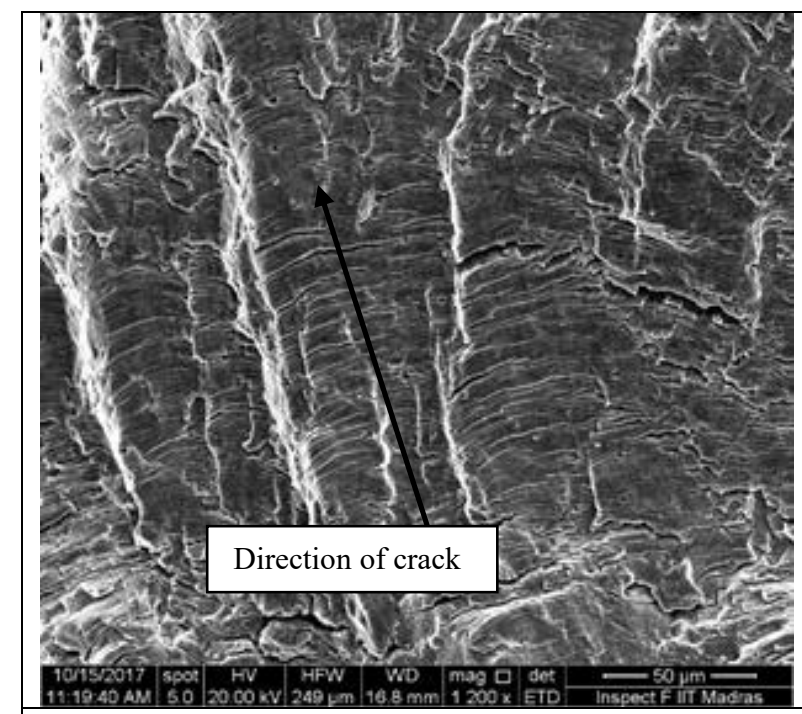

Fig. 12. Observed striation pattern for SS316 MP-TIG joint, located $12 \mathrm{~mm}$ from initiation zone.

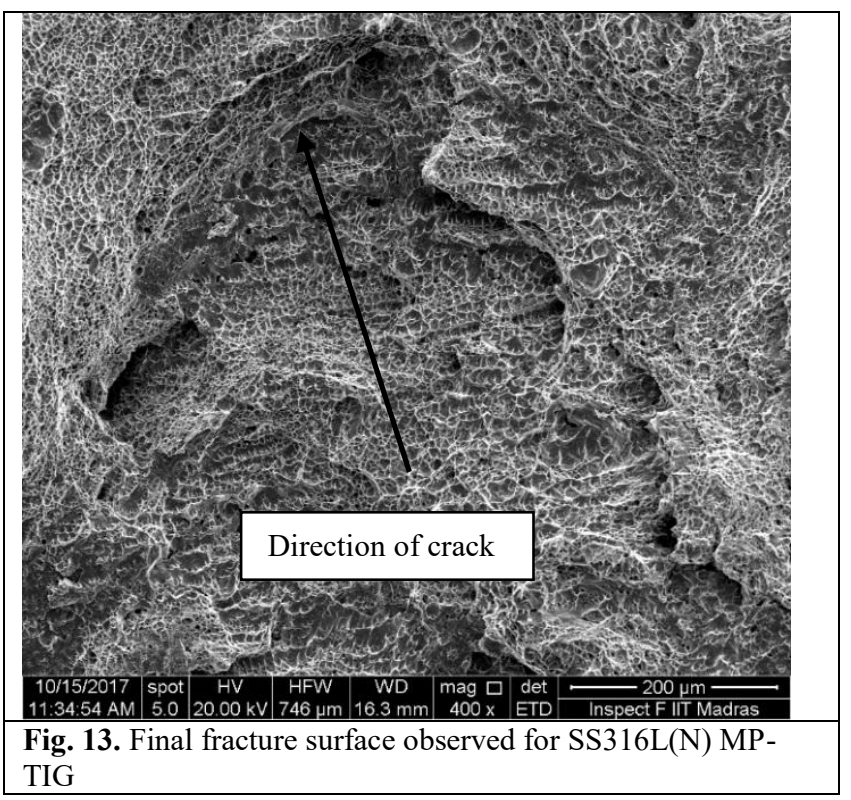

\section{References}

1. W. J. Mills, International Materials Reviews 42.2 (1997)

2. V. Ganesan, M. D. Mathew, P. Parameswaran, K. Laha, Procedia Engineering 55 (2013)
3. V. Ganesan, M. D. Mathew, P. Parameswaran, K. Bhanu Sankara Rao. Transactions of the Indian Institute of metals 63, No. 2-3 (2010)

4. M. D. Mathew, K. Laha,V. Ganesan,Materials Science and Engineering: A 535 (2012)

5. M. D. Mathew, G. Sasikala, K. Bhanu Sankara Rao, S. L. Mannan, Materials Science and Engineering: A 148, No. 2 (1991)

6. A.C. Pickard, R. O. Ritchie J. F. Knott.Metals Technology 2.1 (1975)

7. P. Shahinian, Welding Journal 57, No. 3 (1978)

8. P. Shahinian, H. H. Smith, H. E. Watson, Fatigue at Elevated Temperatures, ASTM International, 1973

9. L.A James, Welding Journal 56, No. 12 (1977)

10. L.A. James, W. J. Mills, Welding Journal 66, No. 8 (1987)

11. K.C. Mills, B. J. Keene, International Materials Reviews 35, no. 1 (1990)

12. M.T. Tanaka,T. Shimizu, T. Terasaki, M. Ushio, F. Koshiishi, Yang C.-L, Science and technology of welding and joining 5, No. 6 (2000)

13. M. Vasudevan, Journal of Materials Engineering and Performance 26, No. 3 (2017). 